\title{
Lip Repositioning with Myotomy- A Surgical Approach to Treat Gummy Smile
}

\author{
Shivaprasad Bilichodmath¹, Geetha K.ㄹ, Ume Sameera³, Paunami Paul4
}

\begin{abstract}
1Professor, Department of Periodontology, Rajarajeswari Dental College and Hospital, Bengaluru, Karnataka, India. 2Postgraduate Student, Department of Periodontology, Rajarajeswari Dental College and Hospital, Bengaluru, Karnataka, India. 3Postgraduate Student, Department of Periodontology, Rajarajeswari Dental College and Hospital, Bengaluru, Karnataka, India. ${ }^{4}$ Postgraduate Student, Department of Periodontology, Rajarajeswari Dental College and Hospital, Bengaluru, Karnataka, India.
\end{abstract}

\section{PRESENTATION OF CASE}

Excessive gingival display also referred as "gummy smile" is one of the major concerns with regard to appearance for many people in this generation. According to Peck et al, an exposure of more than $2 \mathrm{~mm}$ of gingiva during smiling is defined as gummy smile. ${ }^{1}$ Most of the patients complain of unaesthetic appearance due to excessive gingival display during communication and smiling. Gingival display of $\geq 4$ $\mathrm{mm}$ is considered unattractive by both professionals and lay people. ${ }^{2,3}$ This may have a negative influence on one's oral health related quality of life and also can lead to psychological discomfort. ${ }^{4}$

A pleasant smile requires harmony among size, shape, colour of the teeth, gingival health and also an appropriate amount of gingival display during smiling. ${ }^{5}$ An imaginary line following the lower margin of the upper lip during smiling is the smile line. ${ }^{6}$ According to the degree of exposure of teeth and gums, Goldstein classified smile line into 3 types: High, medium, or low gummy smiles (GSs) ranged from mild, moderate, and advanced, to severe. ${ }^{7}$ The display of entire cervico-incisal length of the maxillary incisors and more than $3 \mathrm{~mm}$ of gingiva is the characteristics of a high smile line. When only part of teeth is visible during smiling the smile, line is considered as low and in a medium smile line, 1 to $3 \mathrm{~mm}$ of marginal gingiva is exposed.5,8,9

High smile line is highly prevalent in females (14\% in females, $7 \%$ in males) and occurs in $10.5 \%$ to $29 \%$ of young adults. $8,1,10$ Creating an attractive smile is a challenge and the treatment modality is based on the etiological factor of the excessive gingival display.

The gummy smile is caused due to various etiological factors which are broadly classified into dentoalveolar discrepancies and non-dentoalveolar discrepancies. The altered passive eruption, dentoalveolar extrusion, short clinical crowns, plaque or drug-induced gingival enlargement and vertical maxillary excess are the dentoalveolar discrepancies. Hypermobility of upper lip ((HUL), short, or incompetent upper lip and asymmetric upper lip are the non-dentoalveolar discrepancies. ${ }^{11,12} 20-22 \mathrm{~mm}$ is the average length of the upper lip in young adult females and 22-24 $\mathrm{mm}$ in young adult males. ${ }^{1}$

The cases of excessive gingival display (EGD) can be treated by both surgically and non-surgically. Gingivectomy or an apically repositioned flap associated with or without osseous resection is used to treat EGD caused due to the altered passive eruption, short clinical crowns ${ }^{11,13-15}$. Vertical maxillary excess is treated with orthognathic surgery and dentoalveolar extrusion is usually treated with the orthodontic intrusion.1,2,6,16,17 Various treatment modalities such as Botox injections ${ }^{18}$, lip elongation associated with rhinoplasty ${ }^{19}$, detachment of lip muscles by myectomy and myotomy 20,21 , and lip repositioning 22 are employed to treat hypermobility of upper lip.

Lip repositioning technique was introduced into the field of dentistry by Rosenblatt and Simon in 2006 and it is the modification of the lip repositioning technique first introduced by Rubinstein and Kostianovsky as part of medical plastic surgery in 1973. It has been proposed as a conservative permanent surgical technique that offers a less invasive approach to EGD. The objective of this technique
Corresponding Author:

Dr. Shiva Prasad Bilichodmath,

Professor,

Department of Periodontology,

Rajarajeswari Dental College and Hospital, No. 14, Ramohalli Cross, Mysore Road,

Kumbalgodu, Bengaluru-560074,

Karnataka, India.

E-mail: drspbmath@gmail.com

DOI: $10.14260 / j e m d s / 2019 / 550$

Financial or Other Competing Interests: None.

How to Cite This Article:

Bilichodmath S, Geetha K, Sameera U, et al. Liprepositioning with myotomy- a surgical approach to treat gummy smile. J. Evolution Med. Dent. Sci. 2019;8(31):2526-2529, DOI: 10.14260/jemds/2019/550

Submission 31-05-2019, Peer Review 15-07-2019,

Acceptance 22-07-2019,

Published 05-08-2019. 
is to minimise the excessive display of gingiva by limiting the retraction of the elevator smile muscle (e.g., zygomaticus minor, levator anguli, orbicularis oris, and levator labii superioris. $)^{23}$. Lip repositioning technique should be employed when there is an adequate width of the attached gingiva and vertical maxillary excess is mild to moderate.

The present case report describes the surgical technique and outcome of lip repositioning with myotomy technique to treat excessive gingival display. Compromised esthetics due to excessive gingival display (EGD) or gummy smile has become a major concern for many people of this era. Treatment modalities differ, depending upon the etiology responsible for EGD. This case report demonstrates a case of a 25 -year-old female patient with EGD caused by hypermobility of the upper lip (HUL) which is successfully managed with a less invasive lip-repositioning procedure with myotomy technique. Surgery was carried out by removing a strip of mucosa from the maxillary buccal vestibule, and then dissecting the muscle fibre attachment leaving the midline frenum intact. Finally, the lip mucosa was sutured to the mucogingival line. The Patient was evaluated after 1 month, showed a reduction in the EGD and satisfactory treatment outcome. This technique was efficient in reducing the amount of exposed gum during smile and is an alternative approach to invasive surgical technique with the reduced chance of relapse.

\section{CASE REPORT}

A 25-year-old female patient reported to a private dental clinic with the chief complaint of unaesthetic appearance while smiling due to excessive display of gums. (Figure 1) The patient was systemically healthy, and the familial history was not significant. On extra oral examination, the face was bilaterally symmetrical with competent lips. The length of the lip was normal. High smile line was noted on smiling, with 5 $\mathrm{mm}$ of excessive gingival display extending from maxillary right premolar to maxillary left premolar region. (Figure 2) Intraoral examination revealed good oral hygiene and periodontal health. Adequate width of the attached gingiva was present. (Figure 3) The clinical crown length was in normal anatomic proportions. The diagnosis of hypermobility of the upper lip was made as there was a gingival display of $>$ $4 \mathrm{~mm}$. The patient also exhibited a moderate amount of vertical maxillary excess.

Various treatment modalities such as orthognathic surgery and lip repositioning technique, their benefits, and possible complications were explained to the patient. The patient preferred a less invasive lip repositioning technique to obtain an aesthetically pleasing smile. The written informed consent was obtained from the patient prior to the surgery.

\section{Surgical Procedure}

Disinfection was carried out initially using $2 \%$ betadine solution extraorally and with $0.2 \%$ chlorhexidine gluconate solution intraoral rinse for $1 \mathrm{~min}$. Infiltration of local anaesthesia (2\% lignocaine hydrochloride with 1:80000 epinephrine) was administered in the vestibular mucosa from the maxillary right to left first molar. Sterile haematoxylin pencil was used to mark the incision lines on the dried tissue. Using no. $15 \mathrm{C}$ blade, a partial thickness horizontal incision was made $1 \mathrm{~mm}$ coronal to the mucogingival junction extending from the midline to the distal of the second premolar. At the extremities of the first incision 2 vertical releasing incisions were made. Parallel to the first incision, a second horizontal incision was made at the base of the vestibule, joining the two-vertical incision at a distance double the amount of gingival display. After the incisions are made partial thickness flap was raised and epithelium was removed completely within the outline of incisions and underlying connective tissue was exposed. (Figure 4) The outline of the surgical site was elliptical. (Figure 5) Later, myotomy was performed by dissecting the muscle fiber attachment present in vestibule underneath the flap. The mucosa was advanced and sutured at the mucogingival junction using continuous interrupted sutures (Coated VICRYL $\AA$ polyglactin 910) and the procedure was repeated on the contralateral side leaving the midline frenum intact. (Figure 6) Oral antibiotics (Amoxicillin $500 \mathrm{mg}$ twice daily for 5 days) and analgesic (ibuprofen $400 \mathrm{mg}$ thrice daily for 3 days) were prescribed after surgery. The patient was also advised to apply an intermittent ice pack over the upper lip for the next 24 hours to reduce the postoperative swelling and to minimize the lip movement.

Sutures were removed after two weeks. Post-operative healing was uneventful with no history of ecchymosis or swelling. The patient was satisfied with the improvement in the appearance of smile and was recalled after 1 month for review. (Figure 7)

\section{DISCUSSION}

A smile plays a substantial role in facial expression and appearance. Smile is a complex gesture that involves the position of the lips, condition of the oral tissues and the gingival margin. ${ }^{24}$ Many people in this era desire to have an attractive smile. ${ }^{25}$ In the present case, the patient had an undesirable smile due to excessive display of the gingiva. Evaluation of the aetiology of the gummy smile is necessary to choose the appropriate treatment. Excessive gingival display may be caused by vertical maxillary excess, altered passive eruption, hypermobile upper lip, short upper lip, and gingival hyperplasia.

A study conducted to determine the prevalence of the hypermobility of the lip in a population of patients seeking to correct their gummy smile has shown that HUL is the predominant aetiology and is present in $80 \%$ of them. And it is often present in combination with other etiological factors. ${ }^{26}$ In the present case HUL along with a moderate amount of vertical maxillary excess resulted in excessive display of the gingiva during smiling.

Making the smile attractive is a challenge and requires meticulous treatment planning. The treatment modalities comprise aesthetic crown lengthening, lip repositioning, orthognathic surgery that may be less or more invasive.

Lip repositioning is a simple, less invasive and conservative treatment of this aesthetic discrepancy. A study has shown that lip repositioning successfully improved EGD by $3.4 \mathrm{~mm}$ and is a successful approach for the treatment of EGD, especially for patients with minor discrepancies desiring a less invasive alternative to orthognathic surgery. 
Studies have shown that lip repositioning with myotomy has shown a statistically superior result when compared to that of the traditional technique and also the result achieved was more stable over a period of 12 months. . $^{2728,29}$

Tension during flap closure, post-operative stretching or pain in the upper lip and post-operative discomfort even after suture removal and persistent pain in the operated area was reported in previous cases where the original lip repositioning technique was used. ${ }^{30}$

According to Peck et al., subjects with a gummy smile present 20 percent or more muscular capacity to raise the upper lip, probably because of the increased function of the lip elevator muscles. The myotomy of the levator labii superioris muscles reduces the vertical aspect of the lip elevation by diminishing its muscular function. ${ }^{1}$

In cases with a short upper lip, gummy smile correction with lip repositioning surgery, including elevator muscle detachment was described by Litton and Fournier in 1979. Miskinyar, in 1983, found no relapses for the 27 patients treated with myectomy and partial resection of either one or both of the levator labii superioris muscles bilaterally in lip repositioning surgery.

This case report describes lip repositioning technique with myotomy for the excessive gingival display. Dissection of muscle fibers attachment was done adjunct to the traditional lip repositioning technique in order to allow tension free closure of the flap and suturing. It reduced post-operative patient discomfort and the feeling of stretching over the area. Also, the labial frenum was preserved to establish greater tissue stability. This is a feasible alternative approach with consistent clinical outcome.

Other treatment methods for excessive gingival display due to hypermobility of the upper lip have been mentioned in the literature. The use of Botox injection which contains botulinum toxin represents the fastest, simple and effective method to correct gummy smile. Botulinum toxin blocks the muscular activity has yielded satisfactory results. The toxin must be reapplied periodically to maintain the desired outcome since the results of this non-surgical method are transient and inconsistent. ${ }^{31}$

Incorporating myotomy with lip repositioning has obvious advantages which include tension free flap closure, decrease post-operative pain and discomfort, eliminate the chances of relapse and provides a permanent resolution from gummy smile, thus providing a satisfactory aesthetic outcome.

The surgical procedure yielded better results by achieving a greater degree of gingival coverage. Also, there were no potential complications reported after the 1-month period. The aesthetic demands of the patient were achieved.

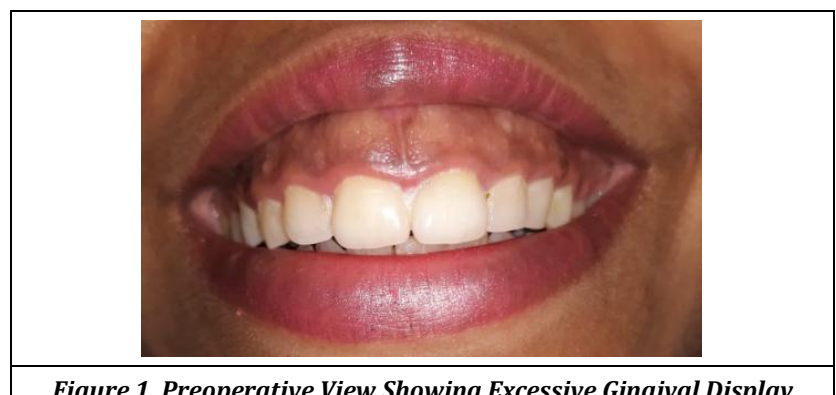

Figure 1. Preoperative View Showing Excessive Gingival Display
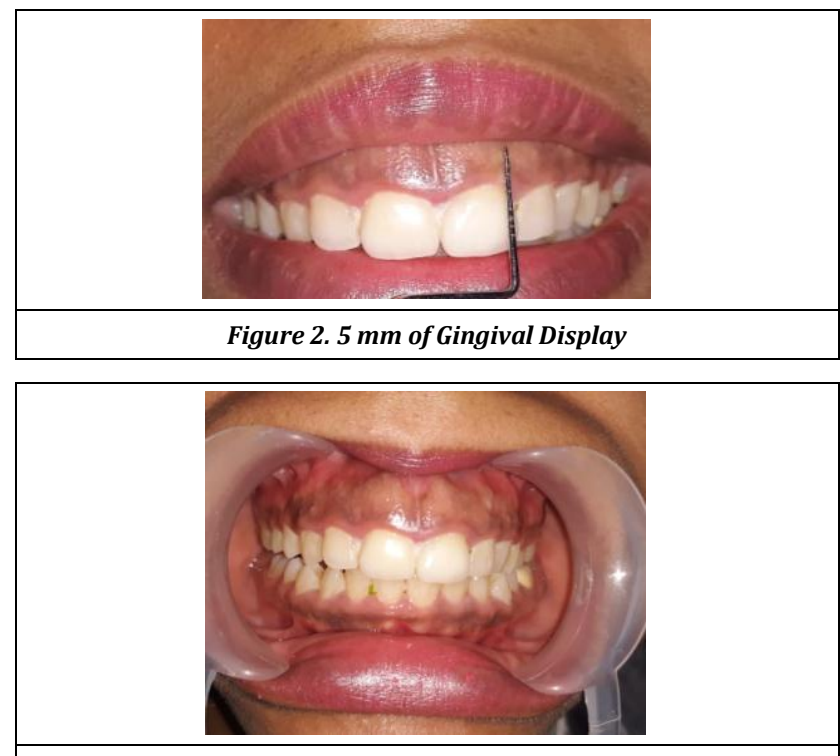

Figure 3. Intraoral View Showing Adequate Width of Attached Gingiva
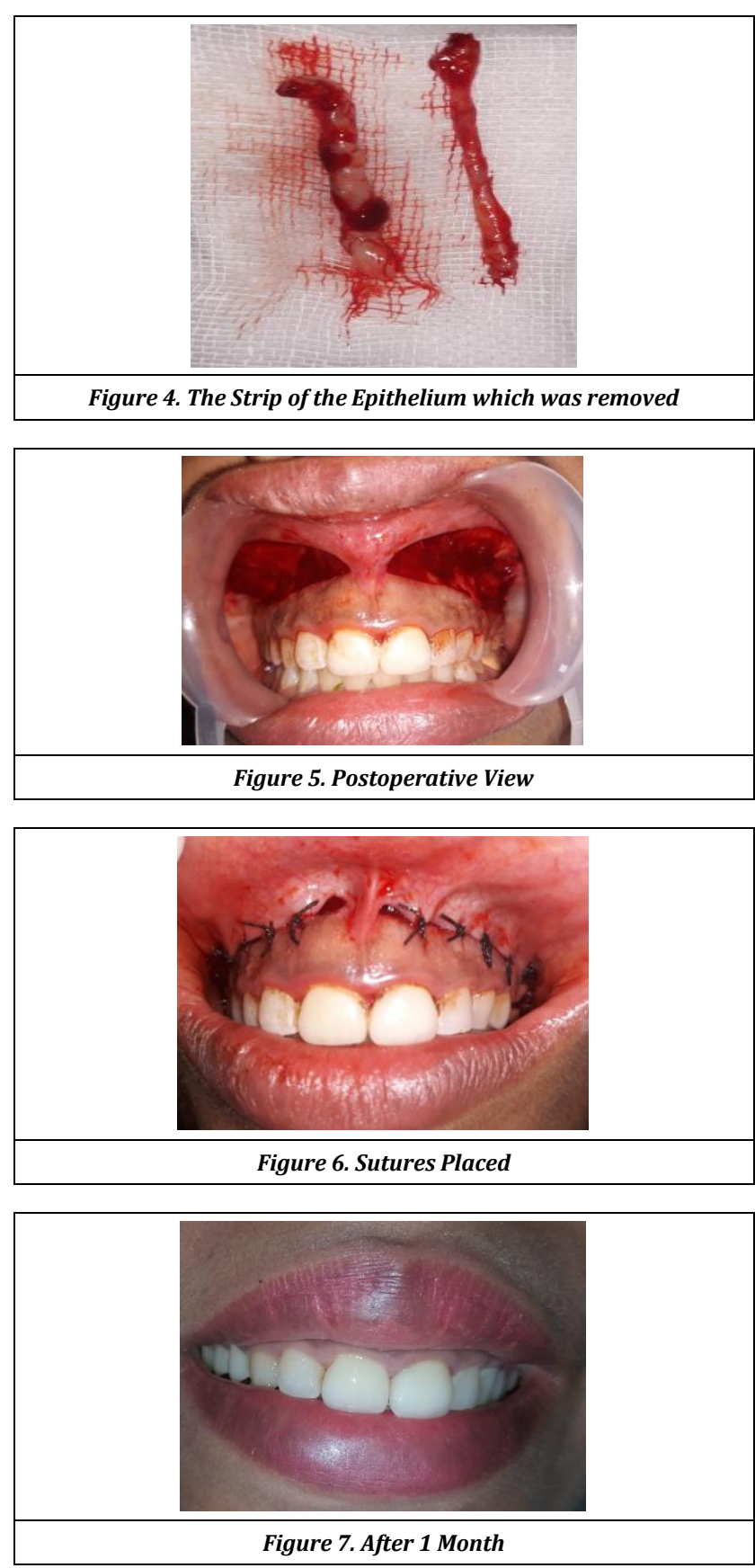


\section{CONCLUSIONS}

Patients seeking treatment for the undesirable gummy smile is more common and it is in demand. Underlying aetiology should be ruled out for the appropriate treatment approach and a desirable outcome. Lip repositioning associated with myotomy is a less invasive conservative approach to treat the excessive gingival display when compared to other surgical procedures. It provides long term results with less chance of relapse.

\section{REFERENCES}

[1] Peck S, Peck L, Kataja M. Some vertical lineaments of lip position. Am J Orthod Dentofacial Orthop 1992;101(6):519-24.

[2] Kokich VO Jr, Kiyak HA, Shapiro PA. Comparing the perception of dentists and lay people to altered dental esthetics. J Esthet Dent 1999;11(6):311-24.

[3] Ker AJ, Chan R, Fields HW, et al. Esthetics and smile characteristics from the layperson's perspective: a computer-based survey study. J Am Dent Assoc 2008;139(10):1318-27.

[4] Cortellini P, Bissada NF. Mucogingival conditions in the natural dentition: narrative review, case definitions and diagnostic considerations. J Periodontol 2018;89 Suppl 1: S204-S13.

[5] Rosenblatt A, Simon Z. Lip repositioning for reduction of excessive gingival display: a clinical report. Int J Periodontics Restorative Dent 2006;26(5):433-7.

[6] Garber DA, Salama MA. The aesthetic smile: diagnosis and treatment. Periodontol 2000 1996;11(1):18-28.

[7] Goldstein RE. Estética em Odontologia. Rio de Janeiro: Ed. Guanabara Koogan, 1980.

[8] Tjan AH, Miller GD, The JG. Some esthetic factors in a smile. J Prosthet Dent 1984;51(1):24-8.

[9] Dong JK, Jin TH, Cho HW, et al. The esthetics of the smile: a review of some recent studies. Int J Prosthodont 1999;12(1):9-19.

[10] Rigsbee OH 3rd, Sperry TP, BeGole EA. The influence of facial animation on smile characteristics. Int J Adult Orthodon Orthognath Surg 1988;3(4):233-9.

[11] Silberberg N, Goldstein M, Smidt A. Excessive gingival display--etiology, diagnosis and treatment modalities. Quintessence Int 2009;40(10):809-18.

[12] Bhola M, Fairbairn PJ, Kolhatkar S, et al. LipStaT: The lip stabilization technique - indications and guidelines for case selection and classification of excessive gingival display. Int J Periodontics Restorative Dent 2015;35(4):549-59.

[13] Evian CI, Cutler SA, Rosenberg ES, et al. Altered passive eruption: the undiagnosed entity. Journal of American Dental Association 1993;124(10):107-10.

[14] Dolt AH III, Robbins JW. Altered passive eruption: an etiology of short clinical crowns. Quintessence International 1997;28(6):363-72.
[15] Weinberg MA, Eskow RN. An overview of delayed passive eruption. Compendium of Continuing Education in Dentistry 2000;21(6):511-4, 516, 518.

[16] Allen EP. Use of mucogingival surgical procedures to enhance esthetics. Dental Clinics of North America 1988;32(2):307-30.

[17] Kim TW, Kim H, Lee SJ. Correction of deep overbite and gummy smile by using a mini-implant with a segmented wire in a growing Class II Division 2 patient. American Journal of Orthodontics and Dentofacial Orthopedics 2006;130(5):676-85

[18] Mazzuco R, Hexsel D. Gummy smile and botulinum toxin: a new approach based on the gingival exposure area. Journal of American Academy of Dermatology 2010;63(6):1042-51

[19] Ezquerra F, Berrazueta MJ, Ruiz-Capillas A, et al. New approach to the gummy smile. Plastic and Reconstructive Surgery 1999;104(4):1143-50.

[20] Litton C, Fournier P. Simple surgical correction of the gummy smile. Plastic and Reconstructive Surgery 1979;63(3):372-3.

[21] Miskinyar SA. A new method for correcting a gummy smile. Plastic and Reconstructive Surgery 1983;72(3):397-400.

[22] Rubinstein AM, Kostianovsky AS. Cirugia estetica de la malformacion de la sonrisa. La Prensa Medica Argentina 1973;60:952.

[23] Tawfik OK, El-Nahass HE, Shipman P, et al. Lip repositioning for the treatment of excess gingival display: a systematic review. Journal of Esthetic and Restorative Dentistry 2018;30(2):101-12.

[24] Robbins JW. Differential diagnosis and treatment of excess gingival display. Pract Periodontics Aesthet Dent 1999;11(2):265-72.

[25] Donitza A. Creating the perfect smile: prosthetic considerations and procedures for optimal dentofacial esthetics. J Calif Dent Assoc 2008;36(5):335-40, 342.

[26] Andijani RI, Tatakis DN. Hypermobile upper lip is highly prevalent among patients seeking treatment for gummy smile. J Periodontol 2019;90(3):256-62.

[27] Ribeiro-Junior NV, Campos TV, Rodrigues JG, et al. Treatment of excessive gingival display using a modified lip repositioning technique. Int J Periodontics Restorative Dent 2013;33(3):309-14.

[28] Silva CO, Ribeiro-Junior NV, Campos TV, et al. Excessive gingival display: treatment by a modified lip repositioning technique. J Clin Periodontol 2013;40(3):260-5.

[29] Ozturan S, Ay E, Sagir S. Case series of laser-assisted treatment of excessive gingival display: an alternative treatment. Photomed Laser Surg 2014;32(9):517-23.

[30] Simon Z, Rosenblatt A, Dorfman W. Eliminating gummy smile with surgical lip repositioning. Journal of Cosmetic Dentistry 2007.23;100-8.

[31] Polo M. Botulinum toxin type A (Botox) for the neuromuscular correction of excessive gingival display on smiling (gummy smile). Am J Orthod Dentofacial Orthop 2008;133(2):195-203. 